Meta

Journal des traducteurs

Translators' Journal

\title{
On the Implausibility of Equivalent Response (Part IV)
}

\section{Qian $\mathrm{Hu}$}

Volume 38, numéro 3, septembre 1993

URI : https://id.erudit.org/iderudit/003147ar

DOI : https://doi.org/10.7202/003147ar

Aller au sommaire du numéro

Éditeur(s)

Les Presses de l'Université de Montréal

ISSN

0026-0452 (imprimé)

1492-1421 (numérique)

Découvrir la revue

Citer cet article

$\mathrm{Hu}$, Q. (1993). On the Implausibility of Equivalent Response (Part IV). Meta, 38(3), 449-467. https://doi.org/10.7202/003147ar

\section{Résumé de l'article}

La plupart des traducteurs admettent l'idée que le fond est plus important que la forme, et que l'un peut être séparé de l'autre. Or, ces deux entités sont aussi inséparables qu'elles sont mutuellement dépendantes. Leur cohésion doit être maintenue à travers le processus traductionnel. Mais d'emblée, lon doit convenir que la notion à l'équivalence est relative, et qu'il n'y a pas de traduction parfaite. 


\title{
ON THE IMPLAUSIBILITY OF EQUIVALENT RESPONSE (PART IV)
}

QIAN HU

Rosemead, California, USA

\begin{abstract}
Résumé
La plupart des traducteurs admettent l'idée que le fond est plus important que la forme, et que l'un peut être séparé de l'autre. Or, ces deux entités sont aussi inséparables qu'elles sont mutuellement dépendantes. Leur cohésion doit être maintenue à travers le processus traductionnel. Mais d'emblée. l'on doit convenir que la notion d'équivalence est relative, et qu'il n'y a pas de traduction parfaite.
\end{abstract}

\section{CHAPTER IV}

MEANING UNTRANSFERABLE

In Nida (1969b: 208), translation is defined as "the reproduction in a receptor language of the closest natural equivalent of the source language message, first in terms of meaning, and second in terms of style." So, after the message has been transferred from the source language to the receptor language, the problems of formal properties or features - style - have then to be considered (1969b: 120). This definition is based on the philosophical assumption that content and form are separable. Such separability is more explicitly detailed in Nida's explanation of the term "dynamic equivalence":

Frequently, the form of the original text is changed; but as long as the change follows the rules of back transformation in the source language, of contextual consistency in the transfer, and of transformation in the receptor language, the message is preserved and the translation is faithful. (1969b: 200)

Whether content and form are separable is the primary concern of this chapter.

\section{The relationship between content and form}

In linguistics, "the interrelationship between form and meaning remains a burning problem" (Sajavaara 1981: 41). As translation is essentially a linguistic activity that concerns the relationship between form and meaning, this problem necessarily enters into translation studies. It becomes additionally complicated and confusing, because two putatively corresponding pairs of form and meaning have to be dealt with simultaneously in any act of translation. Diverse attitudes towards this problem are reflected in prevailing controversies about methodology in translation theory (Rose 1981: 31), especially in the disputes concerning literal versus free translating, and emphasis on form versus concentration on content (Nida 1964: 22). However, the majority of translators and translation theorists accept that content can be separated from form, as Kelly (1979: 56) points out:

translators traditionally have seen the outer form of languages as a vehicule for meaning or content, and have bent the expressive ressources of their target language to fit.

This statement is conformed by the noted metaphor of kernel and shell, which is so influential that it has seldom been questioned: 
Saint Jerome uses his famous image of meaning brought home captive by the translator. We "break" a code: decipherment is dissective, leaving the shell smashed and the vital layers stripped (Steiner 1975: 146).

Geut (quoted in Amos 1920: 146) uses the same metaphor:

I used the freedom of a translator, not tying myself to the tyranny of a grammatical construction but breaking the shell into many pieces, was only careful to preserve the kernel safe and whole from the violence of a wrong or wrested interpretation.

A similar metaphor compares form to clothes (Amos 1920: 158; Steiner 1975: 267). With this view of language, translation is automatically seen as a transfer of meaning from language to language:

Translation is done...from semantic substance to semantic substance, and not between linguistic forms (Morales 1982: 18).

Nida (1969a: 492) describes translation more specifically as "translating bundles of componential features" from a source language to a receptor language, so he (1969b: 145) suggests:

The translator must in a real sense create a new linguistic form to carry the concept expressed in the source language.

The idea of content being separable from form presupposes the constancy of content and its independence of form:

Presumably, the form was language specific; it would undergo transformation from one language to another but the content itself could remain constant (Grace 1982: 6). ${ }^{1}$

In The Added Artificer, which lays heavy stress on the creativity of the translator, Poggioli (1959: 140-141) presents a picture of (literary) translation different from that of Nida's:

Translating is like pouring a new wine into an old bottle; and that if the wine fails to burst the bottle, it is only because the new wine required the old bottle as the only form or frame within which it could rest.

Poggioli looks upon the translator as "a literary artist looking outside himself for the form suited to the expression he wishes to express." The form the translator looks for is not "inborn" but "congenial" to what he is to express (1959: 140-141). In this case, however, what is preserved is form, not content. Although Poggioli uses the words "form" and "content" in a slightly different sense from the linguists mentioned, underlying his argument is his clear belief in the fact the content and form can be separated.

This assumption is untenable. Content and form, although different, are inseparable. Once it takes shape, the content inevitably bears the stamp of the form which substantializes it. If torn apart, the content could not remain intact. This accounts for the impossibility of abstracting content from form completely. ${ }^{2}$ Form is not merely a shell that can be broken to obtain the kernel it contains. It is not already completed, ready to hold a "content;" it comes into being while content takes shape and they occur simultaneously, each feeling the impact of the other. According to dialectical materialism, content determines form while form in turn influences content. They are made for each other in each individual case. In other words, they are simply blended into one, and this state is often called "the union between content and form": no "kernel" can survive an attempt to prise it from the "shell;" to tear them apart is to damage both leaving neither intact. 
For the purpose of this discussion, the relationship between thought and language may be regarded as an illustration of the above argument. As with content and form, thought and language are different concepts. This point is supported by experience; "beyond words," a phrase frequently used when language appears inadequate to express thought, implies the limitation of the power of language and of man's ability to use language. It also demonstrate the different nature of thought and language; despite this, they are closely linked. Once man has acquired a language, he uses that language as a framework for his more complex thoughts, which develop by the use of language. Without language, man's thoughts would be limited to basic and instinctive impulses. Divorced from thought, language is a jumble of meaningless signs; divorced from language, thought is either instinctive (when no language has existed) or insubstantial, and ephemeral (when the thinker is deliberately rejecting language). About the relation of ideas to words, Leopardi (quoted in Steiner 1979: 242) offers a remarkable metaphor of soul and body:

Ideas are enclosed and almost bound in words like precious stones in a ring. Truly they become incorporated in them like the soul in the body, so as to constitute one whole. Ideas are therefore inseparable from words, and if divided from them they are no longer the same. They evade our intellect and our powers of understanding; they become unrecognizable, which is what would happen to our soul if it were parted from our body.

It is inappropriate to compare language to clothes which can be changed at will. An idea, once established, inherently bears the stamp of the language in which it is conceived. Its true existence depends on that language. Divided from language, it withers to the initial cognitive substance. If that cognitive substance subsquently takes form in another language, it is remolded by the language concerned, becoming endowed with various specific characteristics of that language that then become an integral part of itself. It is no longer the same entity, for content and form are mutually dependent in each specific case. Steiner (1975: 82) is correct in pointing out that:

Language does not convey a pre-established or separately extant content, as a cable conveys telegraphic messages. The content is created in and through the dynamics of statement. ${ }^{3}$

This is also true of semantic meaning and linguistic code, which pair content and form together. Like thought and language, they are intimately linked, each pair in its own way. Concerning the relation of meaning to linguistic code, Steiner (1975: 240) says:

Because all human speech consists of arbitrarily selected but intensely conventionalized signals, meaning can never be wholly separated from expressive form. Even the most purely ostensive, apparently neutral terms are embedded in linguistic particularity, in an intricate mould of cultural-historical habit. There are no surfaces of absolute transparency. Soixantedix is not arrived at semantically by the same road as seventy; English can reproduce the Hungarian discrimination between the older and the younger brother, bátya and öccs but it cannot find an equivalent for the reflexes of associative logic and for the ingrained valuations which have generated and been reinforced by the two Hungarian words.

In fact, meaning cannot be separated from expressive form at all. English does not produce "the Hungarian discrimination" between bátya and öccs, but only the English discrimination between the two corresponding English terms - "older brother" and "younger brother." The English discrimination is capable of being used to describe its Hungarian counterpart only in terms of age and no more.

Because of its inseparability from form, meaning is language-relative. It follows, as Quine (cited in Rose 1981: 10) claims, that "sameness of meaning is entirely unintelligible across different languages, and is arbitrary and indefensible within a given language." 
Zhu Guang Qian (1980: 279), a literary critic, holds a similar opinion:

Paying excessive attention to wording seems only to be an act of weighing one's words, but actually it is an adjustment of one's thinking and feelings. No statement, if re-phrased, can keep its significance entirely unaltered.

For instance, the word "spinster" can be analysed into the components "human, adult, female, unmarried," but to describe a woman as a spinster is different from describing her as a female adult human being who is unmarried. To murder is not the same act as to kill deliberately. Although "spinster" may contain only those semantic features denoted by "human, adult, female, unmarried," the combination of them does not add up to or equal a "spinster'. This is also the case of "murder" and "kill deliberately" as has already been discussed.

However, the relationship between content and form is far more complicated than is generally assumed. For example, a word can have several or many senses if the same sense cannot be shared by any two words. How can this phenomenon be explained? It is consistent with the principle of the union between content and form? A Russian lexicographer (.B. Shierba 1981: 33) argues:

It is indeed erroneous to believe that a word invariably has several meanings. This belief arises as a result of approaching the problem only from the angle of form, or even only from the angle of printing. In point of fact, a linguistic word should be regarded as many words as the number of meanings it has (in the dictionaries of the past, words are treated this way; the same word is repeated before each of its definitions). This is a logical inference drawn from the premise that form and content are united. We should, therefore, call a linguistic word a concept word rather than merely a word.

He is right to the extent that the principle of the union between content and form must not be abandoned in the explanation of the phenomenon in question. Yet it is doubtful whether the problem should be approached so rigidly and so mechanically. In this lexicographer's opinion, the union between content and form is of equal correspondence. This seems to be a distortion. The principle of the union between content and form claims their inseparability and their mutual dependence; it does not claim equilibrium in quantity between them. It claims, in other words, each of the two gives rise to the other.

Once established, this union does not remain in the same permanent relationship; it is constantly in a state of flux, and alteration in either content or form inevitably influences the other; hence adjustment takes place which in turn reinforces the relation between content and form. So, alteration in form leads to change in content and vice versa. That change in form can cause change in content is self-evident. However, change in content may seemingly not cause apparent change in form. When a word alters its meaning or acquires a new meaning, its form apparently remains the same, but this is not true if seen in the whole linguistic system. When a word's meaning alters, the coverage of its form over the semantic field alters too. When it gains or loses certain semantic features, the coverage of its form over the semantic field is increased or reduced accordingly; the shape of its coverage on the semantic field changes with the alteration in its meanings.

Since content and form cannot be separated, how can the union between them be maintained in translation? Many translators appear to seek for a union between the content contained in the source language and the target language expressive form; they treat the latter as an empty container, ready to hold the content. ${ }^{4}$ Nida's three-stage procedure intends to achieve such a union, but although it appears to comply with the principle of union between content and form, it actually demands their separation. The separation of 
content from form, in both languages concerned is a precondition for the union between the SL content and the TL expressive form. Since it has been established that content cannot exist apart from its form, then such a union is impossible.

In translation, the content-form union in the source language remains intact and the translator tries to establish a possible TL content-form union, compatible with the corresponding SL content-form union. The reason is obvious; the target language text can be meaningful only provided its content and form are congenially united. In translation, it is obligatory to adjust the verbal form of the translation to the requirements of the communicative process (Nida 1959: 12 ). This is so because the principle of union between content and form must be obeyed by the target language. And the rendering must be compatible with the original so that it may have similar meaning. In translation, the faithfulness to the original and the expressiveness of the rendering seem to be a pair of congruent opposites. Overemphasis on either will damage the other. As faithfulness entails expressiveness and expressiveness - in the case of translation - entails faithfulness, to harm one is to harm both. So, overemphasis is not allowable by the principle of union between content and form and the demanded compatibility between the two compared languages. A translation theorist (Liu B.Z. 1983: 154) maintains that translation criterion should be the unity between faithfulness and expressiveness. To achieve such union, the rendering should establish a unity between content and form in themselves, for the original work has achieved such a unity.

It follows that identity between source language and target language texts either in terms of content or in terms of form is unattainable, for identity conflicts with the principle of union between content and form. Coercion of one in an attempt to make it identical to the other unavoidably destroys the union between content and form in the language under pressure. In every language, content and form are inseparable, and they are united in a unique way. Lyovin (1981: 23) argues convincingly:

What makes different languages different from each other is precisely the differences in the way form and content are related in them. Since for the most part the link between form and content is an arbitrary, conventional one translation can never exactly reproduce the original linkage.

The extent to which the target language text form approximates that of the source language text is to keep the target language content-form union intact. If it goes too far in this respect, that is, as Daniel Huet (cited in Kelly 1979: 76) suggests, translating by language modelled on that of the source text, forbidding any discretion in word-choice or alteration in order, the result could be execrable. It is right only in this sence to say that "adherence to the letter may indeed kill the spirit" (Nida 1964: 16). Similarly, the extent to which the target language text content is allowed to approximate that of the source language text is the degree of compatibility between the two compared entities. The source text is not first translated in content and then translated in form or style into the target language as is the case in the three-stage procedure; both the content and form of the source text are translated simultaneously. The translation can only approximate the translated when each of them is a balanced entity of content and form, established within its own cultural-linguistic surroundings. The principle of union between content and form, and the nature of language as an entity of semantic meaning (content) and linguistic code (form), both deny the possibility for a language to receive and hold with a native empty expressive form an extant meaning from an alien source. They also deny back-transformation and forward-transformation as means by which to obtain equivalence of any type, including "the closest natural equivalence." 6 


\section{Approximation of form}

It is generally agreed by linguists and translators that the aim of translation is to transfer meaning and this is true in the sense that translation is communication. Linguists and translators often fail to agree, however, on the issue of form, as the majority maintain that content is more important than form. They consider form to be like a shell that holds a kernel and the translator is expected to preserve the kernel by breaking the shell into pieces. By encouraging him to translate "sense rather than word" (Milligan cited in Nida 1964: 162$)^{7}$ the proponents of this method appear to regard form as an enemy. For instance, Francis Stoir quotes St. Paul: 2 Corinthians III vi: "The letter killeth but the spirit giveth life" (see Nida 1964: 162). On the other hand, a minority assert that both form and content should be given equal importance. They contend that form should not be ignored altogether, and that the translator is obliged to make his rendering approximate the translated text in terms of form, in order to reproduce the source language meaning precisely. Linguists such as Huet have extended this line of thought, demanding the translator to render with strict formal equivalence, because "the sense could only be transmitted by language modelled on that of the source text" (Kelly 1979: 76-77). For them, "the matérialité of language, the physical aspect, the manner of signification, is exalted over significance itself." (Kelly 1979: 212) There is yet another group of linguists and translators who pay attention to form, while laying particular emphasis on content. The three-stage procedure provides an illustration here. In the procedure, the meaning (content) is first transferred and preserved, and then attention is directed to formal features or style (form).

The various attitudes toward linguistic form reflect various views of language and subsquently various views of translation procedure. A translator's attitude towards linguistic form influences his methodology and therefore to have a correct understanding of linguistic form and its relationship with content is of vital importance.

Linguistic form is not a shell or a container that encloses an independent content which can be separated from the shell. Form itself carries meaning which is inevitably imposed on the content with which it is blended to make an entity. Content develops and becomes fully-fledged in linguistic form through the dynamics of the linguistic system. The linguistic form to some extent moulds the content with which it is blended; so a particular content is congenial to a particular linguistic form, and vice versa.

A few of Bloom's numerous examples - originally used to show the impact of language on thinking — can be quoted here to support this argument. Bloom (1981: 36-37) sees the shift from "sincere" to "sincerity," from "red" to "redness," from "abstract" to "abstraction" and from "to generalize" to "the generalization of" not merely as "a shift from adjective to noun or from verb to noun," but also as a shift that "signals movement from description of the world as it is primarily understood in terms of actions, properties and things, to description of the world in terms of theoretical entities that have been conceptually extracted from the speaker's baseline model of reality and granted, psychologically speaking, a mesure of reality of their own." By adding suffixes such as "-ity," "-ness," "-ance," "-tion," "-ment," "-age," properties and actions can be referred to as if they were things. In fact, they are converted into things by entification (adding these suffixes to the original words), so "gaining a degree of ontological status independent of the things or people who possess them or the actors who perform them." This demonstrates that alteration in structure or word formation changes the semantic meaning of a word as well as its grammatical significance.

According to Bloom (1981: 38-39), the Chinese language "has not had at least until recent data, any mechanism with which to entify properties or actions," although "there are innumerable examples of distinct noun forms that have evolved to capture what are in 
effect the means or results of actions." Influenced by Western languages, Chinese has now developed suffixes corresponding to the English "-ize," "-ism," "-ology," "-ist" and "-itis;" by using these, the words "soft," "modern," and "normal" can be converted into "soften," "modernize" and "normalize;" "society" and "language" into "sociology" and "linguistics;" "science" into "scientist" and "appendix" into "appendicitis." Forms have also emerged for converting a limited number of adjectives into nominal counterparts. With these forms, the adjective "possible" may be converted into a distinct form for "possibility," and the adjective "serious" into a distinct form for "seriousness;" as yet Chinese has no acceptable means for converting "white" to "whiteness," "abstract" to "abstraction" or "subtle" to "subtlety," nor has it means for transforming "accept" to "acceptance" or "generalize" to "generalization." Bloom claims that this deficiency confirms the suggestion that "traditional Chinese linguistic structures did not capture the cognitive implications of entified Indo-European forms, since it is surely for this reason that the new Chinese forms are evolving."

Bloom's discussion regarding entification confirms the impact of linguistic form on its content. With a certain form added, the meaning of the affected word changes, congenial to its new formation. On the other hand, without such mechanism, the notion of entification never occurs. The fact that the ability to generate the notion of entification never occurs. The fact that the ability to generate the notion of entification is in proportion to the evolution of entifying devices in a language - such as Chinese - denotes most clearly the extent to which linguistic form can affect its content.

Steiner's example is also relevant in this connexion. "Soixante-dix" and "seventy" may be said to share the same referential meaning, but access to them cannot be gained in the same way, owing to their different structural formations; difference in formation gives rise to difference in expression which in turn affects interpretation. If the total meaning of a linguistic segment is assumed to be the result of the interpreting process undertaken by the audience, through their knowledge of relevant conventions and linguistic rules, then "soixante-dix" and "seventy" cannot be considered to share exactly the same meaning: they have different semantic structures.

The foregoing examples show how linguistic form as a code-unit affects the meaning it expresses. As syntax, or word order, linguistic form also exerts influence on the meaning it expresses. For instance, the English constructions "The fact that..." and "That..." are capable of "signalling to the listener or reader that the information being conveyed in the subordinate clause is not to be coded on its own terms, but rather in terms of its contribution to an explanatory model being projected." In Chinese, however, there are no structures equivalent to "The fact that..." or "That..." The notion "(The fact) that foreign troops line its borders leads that nation to behave conservatively" can only be rendered into a statement as "Foreign troops line its borders, makes that nation behave conservatively" (Bloom 1981: 46). Although the Chinese rendering closely approximates the content of its English counterpart, it does not carry what Bloom calls "the same cognitive implications." In the Chinese statement, argues Bloom (1981: 47), "the focus of attention falls on the description of two discrete facts as well as on their interrelationship rather than on the fact that one fact is being used to explain the other in a projected theoretical model of explanation." In this case, the two statements express similar content, but the total meaning of the message which one carries is somewhat different from the other. The principal source of disparity between the messages they carry is the divergence between their syntactical structures.

In languages such as Chinese and English, word order is one of the most powerful grammatical or formal devices for conveying meaning. Alteration in sequence can unavoidably cause change in meaning as well as in style: 
(1a) Kè láile. (Guest come -le.) (le is a perfect tense participle)

(1b) lái kèle. (come guest -le.)

There is only a subtle change in meaning caused by the alteration of word sequence in this pair. In (a), the "guest" (Kè) is the one being expected, whereas in (b) it is not (Chao 1968: 76). Although native speakers are able to use the correct sequence spontaneously, they may fail to notice the fine difference between them.
(2a) A dog bites a man.
(2b) A man bites a dog.
(3a) Gŏu yăo rén.
(3b) Rén yăo gŏu.

The change in meaning between (2a)/(3a) and ( $2 b) /(3 b)$ is striking. It is no exaggeration to say that, in the above statements, it is the word order that determines the meaning, for if the sentences are reformulated as:

\#(4a) A dog a man bites.
\#(4b) Góu rén yăo.

they become unintelligible.

The extent to which word order can affect meaning is indicated by Muir's (1959: 93) experience in translating Kafka:

it [word order] not only expresses his meaning but is involved as part of it; only in that order could he have said what he had to say.*

In the light of his argument, word order itself is meaningful ${ }^{9}$ because every linguistic item "operates in the network of formal relations." (Catford 1965: 5) Different arrangements place linguistic items in different locations in that network and they consequently form different relations with the others. These relationships through which linguistic items actually function generate the total message of the complete utterance. On the importance of configuration, a translation theorist (Wang Y.Z. 1983: 192) has the following to say:

When arranged in a certain sequence, ordinary words can be used not only to express ideas, but, more importantly, to express feelings, ambitions, impressions, styles, qualities, etc. They can be compared to the components of millions of organic compounds which are merely those several scores of clements. These elements are capable of composing either sweetsmelling and delicious foods or stinking poisons. Similarly, both the most beautiful music and the most disgusting obscene sound are composed of more than a dozen scales. What makes difference is only the distinctive way in which a given stuff is composed.

It has been illustrated that linguistic form not only carries meaning of its own, but also imposes its meaning on the content to which it is inseparably linked. So it is definitely misleading to compare form (in this case, linguistic form) to a shell or to clothing. And it is also inappropriate to treat it with indifference in the process of translation. To employ the earlier biblical metaphor "the letter killeth, but the spirit giveth life," I maintain that, in effect, form gives life and that life is destroyed when form is broken. The vision of breaking a shell and safely obtaining the undamaged kernel is a fantasy in theory and a mirage in practice.

The necessity of trying to approximate the form of the original becomes a concern to a number of translation practitioners and theorists. However, their methods of approaching the form of the original are very different, ranging from imitation to invention. 
Humboldt and Schleiermacher see "imitation of the minutiae of rhythm, sound and form" as "an essential element of the translator's criticism of his original, a penetration to the inner core of language that transfer of meaning alone could not bring about" (Kelly 1979: 196). There are some grains of truth in this view for if formal features are ignored, transfer of meaning alone is far from satisfactory. Marouzeau (cited in Kelly 1979: 123) agrees with Humboldt and Schleiermacher, claiming the necessity of preserving the internal structure of a segment because "it indicates the expressive priorities of the original." For Batteux (cited in Kelly 1979: 174), the subordination and clause linkage must be kept, for "cette liaison est la vie des pensées et l'objet principal de celui qui parle." In short, the translators and linguists of this group advocate imitating or copying the form of the original and they endeavour to do so. This approach can falter and it can then result in a rendering which is not only at variance with the original in message or in style but is even contradictory in one or both of those fields. Linguists who believe in translating "sense rather than words" see the foregoing weaknesses as an excuse for attacking the method and as a reason for pursuing their own course.

An inventive approach is put forward by Matthews. In the approximation of form, he (1959: 67-68) argues,

the motive is invention, not imitation. The translator has to invent formal effects in his own language that give a sense of those produced by the original in its own. This is working by analogy.

The notion of "inventing formal effects in the target language" ("working by analogy") is good advice to the translator, for it can help him to avoid either of the two usual blunders, either slavishly copying the form of the original or paying too little attention to it. For Matthews (1959: 75), as well as Valery, "the translator's contribution is in the inventions of form" which is regarded as the essence of translation. To translate, then, is "to reconstitute as nearly as possible the effect of a certain cause... by means of another cause..." This approach admits of necessary alterations in form or structure.

Typical of those approaches between the two extremes is the three-stage procedure, which treats content and form separately, placing primary stress on the transfer of content.

It has been demonstrated that the three-stage approach depends upon the separability of content from form, which, in fact, is impossible. The imitative approach demands separability to a greater or lesser degree; rigid imitations of the form of the original will inevitably impair the union between content and form in the target language, for no two languages unite content and form in exactly the same way. In fact, the principal difference between languages lies in the way their content and form are combined to make an entity. ${ }^{11}$ The inventive approach is more flexible than the imitative approach in handling the problem, and is a preferable method although it also copes with form as if it were isolated from content.

Since content and form are an inseparable entity, they cannot - and should not be treated in isolation. On the contrary, they should be processed as an intact entity during the act of translation; this is demanded by the principle of the union between them. As the recommendation to translate "sense rather than words" is partial and incomplete, so is the recommendation to approximate the form of the original. The SL content-form entity as a whole should be approximated, not merely the SL form or the SL content. Similarly, the TL content-form entity as a whole, not merely the TL form or the TL content, should be made to approximate the SL entity. Translators are required to do this and - for the most part - they have always done so in their actual translations.

However, the approximation of the target language entity to that of the source language does not imply the same distance between them in both content and form. They 
may be closer in one aspect than in the other, for, as has already been stated, content and form are linked in a unique way in every language. For example, a rendering of an idiom, though usually having similar meaning, may bear no formal resemblance to that idiom. Such renderings are legitimate because they are intact entities of content and form in the native linguistic system. Therefore, the target language entity which is intended to approximate to that of the source language should have formal effects similar to that of the source language entity, just as it should have meaning similar to that of the source language entity. Only in this way can the target language entity be used as a "translation equivalent" of the source language entity.

\section{Meaning untransferable}

For Jakobson (1959: 233), translation is only adequate interpretation of alien code-units. It is to interpret or substitute the source language messages with those of the target language. It should be noted that in his definition of translation the word interpretation is used. His possible meaning is that to translate is to interpret or describe the meaning of some code-units with that of others; so, to translate an alien code-unit is like explaining the meaning of one native code-unit with another native code-unit. Actually Jakobson (1959: 233) sees the linguistic operations normally called "translation" and "explanation" as having basically the same nature; the former, which he terms as interlingual translation, is "an interpretation of verbal signs by means of some other language" whereas the latter, intralingual translation, is "an interpretation of verbal signs by means of other signs in the same language." 12 Their only difference lies in the different mediums through which they pass.

Similarly, Catford (1965: 20) defines translation as "the replacement of textual material in one language (SL) by equivalent textual material in another language (TL)." For him, "meaning is a property of a language." It is "the total network of relations entered into by any linguistic form." As they enter into two different "total networks of relations," "an SL text has an SL meaning, and a TL text has a TL meaning" (1965: 41). Translators actually replace a source language code-unit with a corresponding target language unit.

The two definitions (and also the two terms interpretation and replacement) imply that translation does not involve the generally assumed transfer of meaning from one language to another. In fact, the principle of union between content and form itself implies a denial of transfer of meaning from one language to another. Not only does translation fail to transfer meaning from one language to another, but meaning itself is considered untransferable. Content cannot be packaged in a form it finds expressively alien. The transfert of meaning is engaged in separating the two corresponding contentform entities from different languages which in reality is not possible.

Catford (1965: 35) points out that every linguistic entity enters into the total network of relations through which it is able to function or express a meaning. As a result, meaning is language-relative. It is a particular network of relations into which a particular linguistic entity enters. Even if the linguistic entity could be transported into another linguistic system, that specific network of relations of which it formed a part cannot be moved into another linguistic system. A language weaves a network of relations peculiar to itself. These networks may exert influence on each other through language contact, but it is irrational to expect one network totally to absorb or to be absorbed by another. A lexical item, for example, is tied into the system of other lexical items. For instance, "boy" is related in one way or another to items such as "girl," "man" and "woman;" its meaning depends on its location in that network of relationships and, divorced from that network, 
it becomes unintelligible. This claim can be supported by the fact of borrowing. When introduced into a target language, a lexical item rarely carries the content it has in the source language. It becomes a "zero word," cut off from its native network of relations. It cannot acquire any content unless it is naturalized in the target language, finding its location in a new network of relations; it then acquires a new content though this may bear a certain likeness to the earlier SL content. The process during which the borrowed item acquires a new content in the target language is that of establishment of a content-form entity. The form, borrowed from an alien source, may seem to remain the same, but its coverage of the semantic field has changed. So, in this sense, it is borrowed - or rather made - for the content with which it is blended to make a new entity. For example, in the hope of communicating their own meaning of "God," early Roman Catholic missionaries in Latin America introduced the Spanish term Dios among Indians who had hitherto worshipped the sun as the supreme deity. As soon as it was borrowed, the term Dios acquired only the meaning of the sun-god, who was then called Tata Dios, "Father God." (Nida 1981: 21) (3) $^{13}$

To transfer the meaning of the word "boy," it would be necessary to transfer the whole network - including "boy" in its location within - into another language. However, it is impossible to transfer the network and translation is never accomplished this way. ${ }^{14}$ A location corresponding to that occupied by "boy" in its native network is indicated with a marker on a corresponding network in the target language. That marker is a target language entity that can be used to replace its English counterpart. One SL contentform entity is replaced with another in the target language. The meaning or content contained in the target language text is the target-language-specific; this point can be illustrated by examining methods used to render proper names, terms and idioms into a target language.

\section{(a) Transliteration of proper names}

The English name "Winter" is rendered as “温德." (wēndé) in Chinese, two ideographs representing two syllables; a more accurate sound representation would be “揾特” (wēntè), for the sound " "

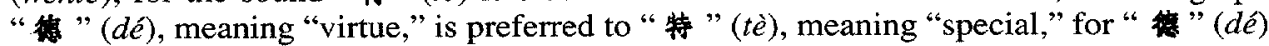
"provides a more pleasant connotation for the orthographic representation of the name" (Jin and Nida 1984: 58-59). Definitely, either the meaning "virtue" or the meaning "special" is not transferred from the English name "Winter," which, if it has any meaning, would only remind us of one of the seasons in which the weather is cold. Ironically, the first ideograph “ 揾” (wên) suggests "warmth," if, in fact, it means anything to the native speaker in this context. There are two Chinese transliterations of the name "Moyer": “移雅” (mùyă) and “毛第” (máoyé). In this case, “移篗” (mùyă) is chosen for its favourable meaning "solemn and elegant;" "毛" (máoyé) is a closer transliteration, but conveys a suggestion of "hairy and wild" (1984: 58-59). Neither "solemn and elegant" nor "hairy and wild" are meanings transferred from the English name "Moyer;" on the contrary, the Chinese ideographs bring them into the target language text. A Chinese transliteration, although intended to be only a sound substitution of its English counterpart, actually replaces it as a content-form entity replaces another. Only in many cases is it expected to be taken merely for a sound representation, and the target language leader is usually prepared to accept it merely as such. In fact, even when an English name is rendered in pinyin ${ }^{15}$ instead of in ideograph, the transliteration still functions as an entity rather than a mere sound representation. In short, a sound representation is a sound representation when the translator and the audience assume it to be so. 


\section{(b) Rendering of terms}

In the Editor's Introduction to Luria, Wertsch (1981: 9) talks about the problem of translating the Russian term "soznanie":

...it might seem that the best solution to the problem of translating the term "soznanie" (consciousness) would be to invent a new term. However, in an attempt to avoid additional barbarisms and to be consistent with existing practices in translation, we have decided to retain the term consciousness throughout the text.

This passage suggests that the English term consciousness - and any of its synonymous terms - simply cannot cover the whole semantic field indicated by the Russian term "soznanie." The meaning of the English term consciousness is narrower, and thereby different from its Russian counterpart; other English synonyms are also inaccurate. Newmark (1981: 167) says: "...concepts when translated (or transliterated) often narrow or deflect their meaning..." If meanings were capable of transference from the source language into the target language, how could they narrow or deflect themselves? The passage also suggests that to translate like this is "consistent with existing practices." So it is normal practice to replace a source language entity with a target language entity which has brought into the target language text its own meaning even though it may be divergent from that of the original entity. This is not a hypothesis but an acknowledgement of a practice already well established.

Wertsch (1981: 9) gives a reason for rendering "soznanie" this way:

It is our opinion that by encountering this term [consciousness] in all of its context in this volume the reader will come to understand what Luria had in mind when he used it.

This implies that the English term may acquire new semantic features through English text conditionning under the sway of its Russian counterpart and this specific original context. It may develop its meaning so that it is more analogous with the Russian term in this particular case. This further implies that the meaning contained in the English term is not transferred from its Russian counterpart, for it is different from that of the Russian term; it also suggests that the newly acquired part of its meaning can only develop itself on the basis of its original meaning in its native linguistic surroundings, though influenced by the language contacted. Therefore, the newly acquired part of its meaning (or new semantic features) is the target-language-relative, and is not transferred from the Russian term either, as is often assumed.

The hypothesis that meaning can only develop or grow in its native linguistic surroundings is well supported by the fact of borrowing or importation. When borrowed, an alien term may not mean much in the borrowing language. Nor has it a definite meaning. Stripped of its native network of relations, it enters the borrowing language naked. Not until it is naturalized will it develop a meaning which may or may not be similar to the meaning it has in the original language. For example, when the English term "humour" was rendered as "youmo" in Chinese, it seemed rather bizarre to the Chinese reader. A Chinese translation theorist (Zeng X.B. 1928: 147) wrote about it contemptuously:

One of the most bizarre examples is the rendering of "humour" into Chinese as "youmo." I wonder who is that great inventor that has bound the two absolute antonyms together in such wedlock? ${ }^{16}$

He scorned the borrowed word because the Chinese term "youmò," although intended to be a transliteration of "humour," bore its own original meaning and consequently brought it into the translating text; also as an imported word, it had not at that time developed a new meaning similar to the current meaning of "humour." However, it has been gradually 
naturalized and has developed the expected meaning through its repeated use, first as a rendering of "humour" and then as an accepted term.

Today, it is no longer considered bizarre and many users may not even be aware of its alien origin. Therefore, Li Pei En (1935: 279) is right when he points out:

When a terminology is first translated into Chinese, the meaning of its rendering may not be very clear or precise. However, with the rendering employed all along for several years, its meaning will gradually become evident. And then the Chinese counterpart of that terminology will find itself naturalized.

His statement "that if it continues to be used like this for a long period, the meaning of a loanword will become evident by itself some time or other" (1935: 279) is not only relevant in this connexion, but is correct in principle concerning the emergence of meaning; for meaning is created through the dynamics of its native linguistic system.

\section{(c) Rendering of idioms}

The German idiom

(5) Mit Wölfen muss man heulen

can be rendered into English either as

(5a) Among wolves one must howl

or as

(5b) When in Rome do as Rome does (Savory 1957: 16) ${ }^{17}$.

Translation (5a) may be said to transfer the meaning from the original idiom. What of (5b)? It is very different both in vocabulary and in syntax. On the problem of idiom translation, Bassnett-McGuire (1980: 24), using the example "menare il can per l'aia" versus "to beat about the bush," argues:

Both English and Italian have corresponding idiomatic expressions that render the idea of prevarication $^{18}$, and as in the process of interlingual translation one idiom is substituted for another. That substitution is made not on the basis of the linguistic elements in the phrase, but on the function of the idiom. The SL phrase is replaced by a TL phrase that serves the same purpose in the TL culture, and the process here involves the substitution of SL sign for TL sign.

That is to say, the mutual substitution is based on their respective meanings or functions from which the receptor can abstract a similar message that serves the same or similar purpose in both cultures. This is also true of (5) and (5b). The substitution of (5a) for (5), however, is based on the linguistic elements and the same image. But it can only be established in the English cultural setting provided it happens to be endowed with the potentiality of engendering a similar message. If it is not allowed by that cultural setting to engender such message, it will unavoidably turn out to be a "false friend" and unable to be established. Strictly speaking, therefore, (5a) replaces (5) rather than transferring its meaning or function.

Idioms provide the most striking examples for illustrating the point that the meaning of words is "at the mercy of the sentences and grammatical patterns in which they occur." (Whorf 1956: 259) In the Chinese four-character idioms "ğ zul bā shé" and "dōng bën xī păo" there is a syntactic force that engenders meanings other than those nor-

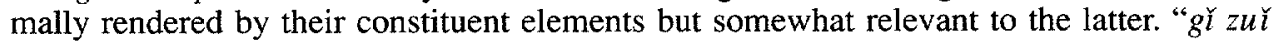


$b \bar{a}$ shê" does not literally mean "seven mouths eight tongues" and "dōng bēn xī păo" does not literally mean "run eastward rush westward." Instead, they mean "talking simultaneously but noisily" and "be busy running about" respectively. In addition, the syntactic force prevents the native audience from taking them literally. However, their English counterparts "seven mouths and eight tongues" and "run eastward and rush westward" do not have such syntactic force and they do not engender meanings other than those conveyed by their constituent elements. They are $N P+$ and $+N P$ and $V P+$ and $+V P$ constructions (normal coordinate structures), while their Chinese counterparts are $A B a b$ constructions where $A$ and $a$, and $B$ and $b$ stand in a relation of mutual contrast-complementation. It is such relations of mutual contrast-complementation that give rise to that syntactic force, which can be evidenced by the fact that any part of such a construction, either $A B$ or $a b$ cannot engender meanings other than those contained in the constituent elements, for the relations of contrast-complementation held between the two parts are destroyed by breaking the whole construction in half.

In the light of this analysis, it can be clearly seen that syntax, being language-relative, engenders meanings which may be "utterly extraneous to the original lexation reference." (Whorf 1956: 261) In other words, such meanings (including syntactic force) are also language-relative.

Because a discourse is composed of sentences each of which " "interwines with' or 'takes in' the meaning of the preceding one" (Luria 1981: 186), the meanings and the force it engenders are language-relative. This deduction may proceed to assert that a whole text is language-relative and this could then account for the translator finding himself baffled and betrayed by his own diligence:

In trying to translate a sequence of events in a systematic and faithful manner, one may find inferences of relations in the receptor language that may not exist in the source document (Nida and Reyburn 1981: 44).

\section{(d) Empirical facts}

The argument that meaning is untransferable can be verified by empirical facts. For instance, a translator who thinks of an expression in the target language in the hope of replacing the original may immediately abandon it because its meaning does not precisely tally with that of the original expression. He will then try to think of another expression more consistent with the original in terms of meaning, bearing in mind terms of style as well. This shows convincingly that the meaning of the target language text does not come from the source language text. A translator writes a text in the target language that matches that written in the source language. If he considers it not close enough to the source, he rewrites it so that the gap between his version and the original might be narrowed. ${ }^{19}$ Theoretically, countless "equaly well-grounded and reasonable translations, all of them mutually incompatible, among which there is nothing to dictate a choice" (Rosenberg 1974: 50) could be produced in the same target language. In reality, it is not unusual to have one or two translations from one source. For example, there are at least three Chinese versions of Jane Eyre and three English renderings of A Dream of Read Mansions. There are even more English versions of the Tang Poems. If translation were indeed a mere transportation of meaning from one container to another there would be no justification for more than one rendering of a source text in any one language.

\section{No perfect translation}

There is no perfect translation and there never will be. "All types of translation," according to Nida (1959: 13), "involves (1) loss of information, (2) addition of information, and/or (3) skewing of information." It is very important to be aware of this fact, as 
Anatole France (cited in Savory 1957: 77) says: "...recognition of that truth is a necessary preliminary to success in the art." In fact, "recognition of that truth" is also indispensable to a correct understanding of translation.

Among these "enormities" (Savory's term for the three types of distortion listed by Nida), the skewing of information is - in most cases - due to carelessness on the part of the translator. Although it happens frequently in practice, it can theoretically be avoided. It is a contingent, but not an inherent problem in the process of translation, so it is not particularly relevant to this discussion.

However, this is not the case with the other two "enormities." Loss of meaning is unavoidable. One of the inevitable source of loss, according to Newmark (1981: 7-8), is the fact that "the two languages, both in their basic character and their social varieties, in context have different lexical, grammatical and sound systems, and segment many physical objects and virtually all intellectual concepts differently." ${ }^{20}$ For instance, Chinese kindship terms "biăxīong," "biăodì," "biăojiěe," "biăomèi," "tángxiōng," "tángdì," "tángjiè" and "tángmèi," when rendered into English, will lose maternal/paternal references and the distinctions of seniority and sex. When English colour terms are replaced by Navaho counterparts, some of the distinctions will be obscured; for the Navaho segmentation of the spectrum is much simpler than the English version. ${ }^{21}$

Some languages use a number of temporal gradations such as past time of a few minutes ago, past time of earlier today, past time of yesterday or recent weeks, past time of a month to a year, and past time of legendary events. In most Indo-European languages there are three basic tenses - past, present, and future, with several tenses of relative time, namely pluperfect, future perfect and past perfect (Nida and Taber $1969 \mathrm{~b}: 116$ ). In translating from a language with a complex tense system to a language with a relatively simple tense system, a good deal of information is likely to be lost. Some languages have more subtle differences of aspect than others. For example, in the Guaica language of Venezuela each complete sentence must end with one of the aspectual particles that indicates whether the described was seen by the speaker, was heard from reliable persons, or is purely legendary or imaginery (ibid.). When a sentence of that language is rendered into Chinese or English, its fine distinctions of aspect will certainly be less distinct.

Differences between two language sound systems cause problems and difficulties, particularly in poetry translating. A good poem ingrained with "vowel music" may readily turn out to be a chain of intelligible noises in another language with its meaning impaired and distorted, for "vowel music" is part of the poet's meaning. ${ }^{22}$ Moreover, a word may be associated through its sound quality with other words that may otherwise bear no relation to it at all. Many puns ${ }^{23}$ are based on such associations, which are entirely language specific. In " 春塞到死丝方尽" (Chüncán dàosĭ sĩ fāngjìn), a line from a lyric by Li Shang Yin, the character “丝” (silk) shares the sound si with “思” (think of), even sharing the same tone, so the poet's delicate play on words has placed the line (and the poem) among the most beautiful ever written. The character “死” (death) also has the same sound, - but with a different tone - and this contributes to the delicacy of the

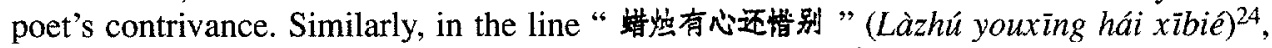
the character "心" (wick) shares the sound xing with “心” (heart, mind), hence the word-play which also personifies the poem. ${ }^{25}$ Such lines translated by "pouring out of one language into another" will not merely fail to convey the message but they will "all evaporate" (Denham cited in Amos 1920: 150-151).

Savory asserts that inevitable loss of meaning can be concealed or condoned by the establishement of a "compensation" principle. He (1957: 86; cf. Kelly 1979: 216) compares the translator to a merchant: 
If a translator finds himself forced to omit something, he may be excused if he offers something else in its place, as if he were a merchant who, having promised to deliver a specified weight of a commodity, has failed to do so and must make amends by the gift of an unexpected bonus.

The idea of "compensation" can be illustrated by the handling of idioms in translation. More often than not, idioms in one language have to be rendered as non-idioms in another. For exemple, if "Zhöngyuán zhúlu" is transferred as "Deer chases [are] hot in the heartland," it is almost impossible for the English reader to abstract the message "fighting fiercely for power" (Xu Y. C. 1984: 166-167), as he lacks an adequate knowledge of its cultural and historical setting, even though the original image has been retained. A shift into non-idioms is necessary at the cost of the image. However, loss of images and etyma can be condoned or compensated by rendering non-idioms as idioms whenever the chance arises. If the translator is sufficiently sensitive to such chances and "compensate for loss of certain idioms by the introduction of others," the figurative force of the translation will not be weakened (Nida Taber 1969: 106).

It seems, however, that "compensation" such as the shift from non-idioms to idioms, is optional, unlike that from idioms to non-idioms which is compulsory. Whether or not to render non-idioms as idioms largely depends on the translator's personal interest and it is in some ways a matter of technique. But, compulsory addition of information, like loss of information, is necessarily enforced by translation. ${ }^{26}$ For example, the rendering of the English kindship word "cousin" into Chinese inevitably involves addition of information. This is also true of translating other kindship words such as "aunt," "uncle," "parent," "grandfather" and "grandmother." Similarly, the translation of a Chinese sentence into the Guaica language of Venezuela cannot fail to gain subtle distinctions of aspect, and information is necessarily added.

If those "enormities" are examined carefully, it will be seen that the "loss" in the process of rendering, say, a Chinese kindship word for "cousin" into english is the "gain" in the reverse process when rendering "cousin" into Chinese. The same amount of information that is lost as result of the movement from the Guaica language into Chinese will be gained as a result of the movement from the latter into the former. That which is lost is inherent to the source language and absent in the target language; that which is added is inherent to the target language and absent in the source language. When a loss or gain is noted, the problem is seen from the angle of the source language. Actually, nothing is lost nor added, and to talk of "loss" or "gain" is misleading. These terms are a result of misunderstanding the nature of translation, and in turn they give rise to a misconception of translation. The so-called "loss and gain of information" are really differences between the two languages revealed by their contact during translation in the sense of substitution or replacement. It has already been shown that translation is the substitution of a target language entity for a source language entity. It is not replacement of part of the source language entity with part of the corresponding target language entity because content and form are inseparable. Since no two languages are identical, no two entities from different languages will be identical. It follows that differences between them (loss and/or addition of information) will be unavoidably revealed in the process of substitution. In effect, translation, though it seeks for equivalence, entails differences. Without differences, no translation would be practically needed. It is "equivalence in difference" (Jakobson 1959: 233). The substitution of one entity for another is made on the basis of analogy, not of sameness.

This being the case, identical equivalence is only an unrealistic dream. The socalled "formal and dynamic equivalences," if not misleading, are at best a matter of degree. Even the most flexible concept, "the closest natural equivalence," may prove to 
be inappropriate. For example, in Chinese, the closest natural equivalents to the English words animal, vegetable, mineral and monster are "dòng wù," "zhí wù," "kuàng wù," and "guài wù," but they are not truly equivalent. The Chinese counterparts all have the character "wü" (object) as a head word, modified by various adjectives: "dòng wü" means "moving object;" "zhí wù," "vegetable object," "kuàng wù," mineral object;" and "guài wù," "strange object." They are all objects. The character "wü" actually subsumes them under one very abstract, philosophical concept, creating an association among them. When spoken, particularly by animal characters in a fantasy world, they sound like rhymes or play on words, all with "wü' at the end. By contrast, the English words "animal," "vegetable," "mineral" and "monster" have no formal features to tie them together. Of course, they can be grouped under one abstract philosophical concept, not by linguistic means, but through knowledge of the empirical world and the natural sciences. The concept "object," if any, is unclear, submerged in the other transparent semantic features which the English words hold. They share no apparent linguistic or semantic features, nor can they create a sound pattern as do their Chinese counterparts. If the Chinese counterparts can be called the closest natural equivalents, they may well be called overtranslation (cf. Chao 1969: 166), which is more appropriate and risks no misunderstanding.

The attempt to find the closest natural equivalents may be unprofitable. The English renderings of the Chinese term "shénxiän" in All That Must Be Done Is Done, a poem in A Dream of Red Mansions, provides a good example here. The poem is coloured with Taoism; so is "shénxiānn" if it is not a Taoist term. Therefore, to replace "shénxiān" with "salvation" results in a slightly less faithful rendering, for "salvation" introduces "an element of Christianity which is alien to ancient Chinese." The word "immortal" "seems to be more faithful to the Chinese Taoist ideal contained in the original poem." (Jin and Nida 1984: 97) Even if one admits that "immortal" is more faithful to "shénxiän" in this case, does it really provide the english reader with an atmosphere of taoism? If so, what does taoism mean to him? And what does it mean to the native reader? Just as Christianity is alien to ancient Chinese, so Taoism is alien to the average English reader and the meaning to the two audiences is necessarily different.

Christianity is the major religion in English culture, and Taoism is also a major religion in Chinese culture, having originated in Tao's philosophy. They both have played an important role in their respective societies. On the analogy that modern European prose is considered a dynamic equivalent of the ancient Greek epic, since they are both prevailing genres in their own ages and societies, Christianity and Taoism could be counted as dynamic equivalents. Again, on the analogy that modern European prose is assumed to be able to elicit a response from the modem European audience equivalent to that which the Greek epic aroused in ancient greek audiences, "salvation" could be expected to be capable of the same reaction. Similarly, if "a hearty handshake" can be taken for a dynamic equivalent to the nonsexual religious kiss and expected to elicit equivalent response, there is small justification in denying "salvation" as dynamic equivalent to "shénxiān" and doubting its capability to trigger equivalent response. Only it is less faithful to the original, and in the final analysis it is different from "shénxiän" in terms of meaning, style and function despite a certain degree of compatibility between them. And different concepts cannot produce the same effect, just as different stimuli cannot cause the same response. Therefore, "salvation" cannot elicit a response equivalent to what "shénxiān" has done, even though, it is a dynamic equivalent of "shénxiān" — and neither can "immortal."

Also, the closest natural equivalents may stand in a contradictory relation with dynamic equivalents; "immortal" in this case is the closest natural equivalent, but it does not form a base for building up dynamic equivalence as is intended to. On the contrary, the dynamic equivalence is "salvation," which is considered insufficiently faithful to 
produce an equivalent effect (to elicit equivalent response) whereas dynamic equivalence is expected to do so.

If this line of argument is logically extended, it is demonstrable that no equivalent response can be obtained, since there are no two linguistic entities that are truly equivalent. In fact, every translation is a "new birth in the new tongue" (cited in Nida 1964: 233). It is probably in this sense that Carne-Ross suggests the use of the term "transposition" instead of "translation," because " translation' is supposed to 'give you the original" (Kelly 1979: 216). As translation entails differences, Ida Rhodes is right when she points out that "translation" and "mistranslation" have the same connotation (ibid.).

\section{Notes}

1. Cf. Quine (1959: 148): "Empirical meaning is what remains when, given discourse together with all its stimulatory conditions, we peel away the verbiage. It is what the sentences of one language and their firm translations in a completely alien language have in common."

2. Even in producing a dictionary for a computer, both meaning and structure must be constantly considered together. See Nida (1964: 261).

3. Cf. Lei H.Z. (1951: 254): "If there are quite a few formal disparities between the two renderings of one and the same source, they cannot be one hundred percent appropriate and precise, that is to say, they cannot be absolutely faithful to the original work. And this has just proved the inseparability of ideas from the language in which they have taken shape." $C f$. also Sapir (1921: 14): "Language is primarily a prerational function. It humbly works up to the thought that is latent in, that may eventually be read into, its classification and its forms; it is not, as is generally but naively assumed, the final label put upon the finished thought." Hou F. (1982b: 76): "Chomsky is convinced that people are unable to capture a formless meaning floating in the air, and then create a form to cxpress this "meaning'."

4. Cf. Xu Yuan Chong (1984b: 134): "Translating is an art in which one language form is used to express the content already expressed in another language. Its main task is to solve the contradiction between the content of the original work and the form of the target language." See also Nida and Taber (1969b: 145).

5. Cf. Peng Q.L. (1980): "A translator's task is to represent the unity of content and form of the original work in another language so that the union of the form and content of the target language is achieved. What we call 'the union of the form and content of the target language' must not be metaphysically interpreted as 'absolute equivalent', for this does not tally with the actual comparative relation between English and Chinese, nor with the actual situation of many good translations. In other words, absolute equivalence cannot be achieved in most cases and therefore it is not a scientific idea."

6. Nida himself holds the view that content and form are inseparable. See Nida (1964: 164); see also Jin and Nida (1984: 103). But his theory and method often run counter to this stated opinion, see Nida and Reyburn (1981:61-70).

7. Ezra Pound, too, demands "more sense and less syntax," see Nida (1964: 162).

8. Sentences marked with \# are anomalous and incorrect.

9. Bassnett-McGuire (1980: 102-103): "Arrangement itself is meaningful."

10. $\mathrm{Cf}$. Whorf (1956: 83): "...the far more important thought materials [are] provided by structure and configurative rapport."

11. Cf. Lyovin (1981: 23): "... what makes different languages different from each other is precisely the differences in the way form and content are related in them."

12. Jakobson distinguishes three types of translation: intralingual, interlingual and intersemiotic translation. The last one is defined as "an interpretation of verbal signs by means of signs of nonverbal sign systems. See Bassnett-McGuire (1980: 14).

13. Cf. Ge Chuan Gui (1983: 95): "Some loanwords cannot be translated back into their source language - for instance, 'lǔxiăngde' (ideal) in 'Tāde gẽ chàngde bù(goù) ľ̌xiăng' cannot be put into English as 'Her singing is not ideal', since, idiomatically, the English word 'ideal' is not used in negative sentences - and this shows that the word, introduced into Chinese through translation, has already been naturalized in the language with extension in its significance and usage; as a result, it is no longer fully equivalent to the original word - ideal."

14. Cf. Snyder (1981: 134): "...the attempt to carry the semantic relationships of one language into another is by their nature impossible."

15. Chinese pinyin is a system which is employed to represent sounds of characters by spelling them in letters.

16. According to Zhou Xu Liang (1983: 265-277), Lin Yu Tang first rendered "humour" into Chinese as "youmò." 
17. This is Savory's version; a more usual version among English speakers is "When in Rome, do as the Romans do."

18. "To beat about the bush" is an idiom expressing extended digression rather than prevarication.

19. $C f$. Lattimore (1959: 49): “...what you are improving may be not the Greek, but just your own English version." Note that the word "write" here is used in the sense of "working by analogy," not in the sense of expressing oneself rather than the original author.

20. Newmark (1981: 7-8) lists four sources of loss: involvement of elements peculiar to the natural environment, institutions and culture of its language area, difference between the ways in which the writer and the translator use language, and the fact that they have different theories of meaning and different values.

21. Biăo indicates the relationship between the children or grandchildren of a brother and a sister or of sisters. Táng indicates the relationship between cousins of the same paternal grandfather or great-grandfather. $X$ iong: elder brother; di: younger brother; jiě: elder sister and mèi: younger sister. However, the English counterpart of all these Chinese kindship terms is cousin. For a comparison of the two sets of colour words, see Catford (1965: 51).

22. Cf. Figueroa (1982: 72): "I hold it as axiomatic, of course, that the vowel music referred to, and the laryngobucal operations mentioned above are part of Virgil's meaning - not added beautification of it!"

23. The word "pun" has become associated with humorous word play and is generally used in this way although there are many examples of play on words - as in the following examples - that are sensitive and not humourous.

24. This line is taken from the poem Parting (II) by Du Mu, a well-known Tang poet. For translations of these lines, see notes 4 on page 116 .

25. Note that in modern Chinese the character for "wick" is " which is strictly distinguised from " $心$ " (heart, mind) in orthography. But in this line, the ideograph " $\$$," which of course may be considered as a metaphor, is purposely used instead of " However, there is a tendency to assume that it is word-play. As it is, there is reason to claim that the character "N" here is "borrowed" to represent the sound xing that stands for "wick," a phenomenon called "tongjiă" in Classical Chinese. If this assumption is tenable, then it is impossible to decide whether the character " $"$ " is intended to refer to “" $w$ " (heart, mind), or " or both. The two images are simply fused into one, typical of the fine contrivance of the poem as a whole.

26. $C f$. Qian Z.S. (1979b: 1263): "Some of the source language qualities will inevitably be lost, otherwise translation is impossible... Changes in word order will lose the spirit of Sanskrit, whereas the original sequence of words can only be retained at the cost of the expressiveness in Chinese. In translating, therefore, you are not to be blamed for having lost something pertaining to the original text, because you have had to lose something in the source language so as to gain something else for the reader of the target language." 